\title{
Marcin Kujawa \\ Selected local stability problems of channel section flanges made of aluminium alloys
}

Received: 24 May 2018 / Accepted: 9 August 2018 / Published online: 22 August 2018

(C) The Author(s) 2018

\begin{abstract}
The paper addresses the issue of local buckling of compressed flanges of cold-formed thin-walled channel columns and beams with nonstandard flanges composed of aluminium alloys. The material behaviour follows the Ramberg-Osgood law. It should be noted that the proposed solution may be also applied for other materials, for example: stainless steel, carbon steel. The paper is motivated by an increasing interest in nonstandard cold-formed section shaping in local buckling analysis problems. Furthermore, attention is paid to the impact of material characteristics on buckling stresses in a nonlinear domain. The objective of the paper is to propose a finite element method (FEM) model and a relevant numerical procedure in ABAQUS, complemented by an analytical one. It should be noted that the proposed FEM energetic technique makes it possible to compute accurately the critical buckling stresses. The suggested numerical method is intended to accurately follow the entire structural equilibrium path under an active load in elastic and inelastic ranges. The paper is also focused on correct modelling of interactions between sheets of cross section of a possible contact during buckling analysis. Furthermore, the FEM results are compared with the analytical solution. Numerical examples confirm the validity of the proposed FEM procedures and the closed-form analytical solutions. Finally, a brief research summary is presented and the results are discussed further on.
\end{abstract}

Keywords Cold-formed members · Local buckling · FEM · Closed-form analytical solution · Nonlinear analysis · Aluminium alloys

\section{Introduction}

Cold-formed thin-walled aluminium alloy members are increasingly being applied in many engineering structures because of their low weight, relatively high mechanical strength and inherent corrosion resistance. An increasing demand for this structural class also results from their simple manufacturing and assembly technology. Unfortunately, in the case of cold-formed thin-walled structures, the ability to carry relatively high loads can be limited not only by material strength but also by structural stability. To achieve stability, mostly in a local extent, more complex shapes of cold-formed thin-walled column and beam sections are used. Shape changes of cross sections result mainly from the need for shape optimisation.

The joint domains of fundamental theory and methods of stability analysis and optimal structural design under stability constraints are well developed in both analytical and numerical regard $[11,17,24,26,27,33,47$, $49,58,59]$. Two general classes exist in the field of stability analysis: amplification methods and energy methods. The amplification methods (also known as von Neumann stability analysis) are based on decomposition of

Communicated by Francesco dell'Isola.

M. Kujawa ( $\varangle)$

Department of Structural Mechanics, Faculty of Civil and Environmental Engineering, Gdańsk University of Technology,

G. Narutowicza 11/12, 13, 80-233 Gdańsk, Poland

E-mail: mark@pg.edu.pl 
motion into normal modes, for example using Fourier analysis, and superposition. This approach can be implemented by means of standard linear procedures; thus, it is limited to linear problems only. Nevertheless, in some cases, nonlinear systems can be solved by means of linearisation. While the energy methods (also called Lyapunov methods) are based on measures of the motion amplitude, they are not restricted to linear systems. Therefore, energetic approach is especially recommended in the cases of nonlinear systems and in advanced problems of structural stability analysis.

Nowadays, the generalised beam theory (GBT) $[9,46,57]$ or alternative theories of plates and shells $[15,16]$ are applied to study the structural behaviour of thin-walled members. The research is mainly focused on thinwalled members made by steel or aluminium, but not only for them [6]. Particular attention should be given to the review articles by Davies [12] and Hancock [20,21] and to the books by Mazzolani [39,40], Kissell and Ferry [23] and Rondal and Dubina [13]. The years of research have not been sufficient to thoroughly solve the problems of stability loss, which is of a sudden nature and difficult to contain. The stability loss problems are subject to ongoing research $[18,31,32,52,54]$. Experimental research is still being conducted to investigate the phenomenon of stability loss, to verify the proposed analytical or numerical solutions and to improve the direct strength method (DSM) [7,25,41,45,62]. The major work that is closely related to the issues raised in this paper on elastic and inelastic buckling of members of cross sections with nonstandard flanges is the experimental and analytical research conducted by Magnucki and his colleagues [34-36,42-44]. Many other researchers have recently addressed these issues $[28,37,38,61]$. Alongside experimental research, the development of numerical methods is still in progress. The recent numerical research is primarily focused on the finite element method (FEM) [2,5], the finite strip method (FSM), the constrained finite strip method (cFSM) [3,4,29,51] and the semi-analytical FSM [22]. Computations are generally performed using non-commercial solvers such as CUFSM [30] (elastic buckling analysis of thin-walled members with general end boundary conditions), CUTWP [53] (global buckling analysis of thin-walled members), GBTUL [1] and authors' solvers such as SAFSM and reSAFSM [21]; commercial programs (e.g. ABAQUS [19]) are also applied.

The stability analysis of cold-formed cross-section members with nonstandard shapes showing normal and tangential interactions with friction between sheets of nonstandard flanges/walls is a current research issue. The research is decisive when the thin-walled structures are composed of nonstandard materials such as aluminium alloys or composites.

This paper considers the local buckling of compressed flanges of cold-formed thin-walled channel columns and beams with nonstandard flanges composed of aluminium alloys [50]. The material behaviour follows the Ramberg-Osgood law [48] in a nonlinear range. It should be noted that the Ramberg-Osgood constitutive equation may be also applied for other materials, for example: stainless steel, carbon steel or even wood, and in these cases, it is possible to use the method of stability analysis presented herein. A finite element method (FEM) model and a numerical procedure with the use of the commercial software ABAQUS are proposed here. Furthermore, an analytical solution is also presented [55]. Comparison of the FEM solutions with the analytical results is finally presented.

The main inspiration to taken discuss about problems of the local stability of non-standard cross-sections (see Fig. 1b, c) is a proper modelling of cooperation of two flanges sheets, what is already suggested in paper [55]. The case of neglecting the inter-sheet contact introduced to the ABAQUS system results in the critical buckling stresses even a 50\% lower, compared to the contact case [55]. Furthermore, for some commonly used programs, for example CUFSM, it is not possible during analysis to consider the influence of contact and material nonlinearity at all. It should be emphasised that the error concerns not only the value of critical stress but also the mode of buckling.

The original aspects of the paper are proposals of analytical approach and energetic numerical approach in system stability analysis, in linear and nonlinear range, focused on correct modelling of interactions between sheets of cross section with a possible contact during buckling.

\section{Analytical approach}

Let us consider compressed flange types A, B and C (see Fig. 1) of a thin-walled channel column or beam of length $l$, as shown in Figs. 2 and 4 [55].

An elastic connection is modelled in the form of distributed elastic springs of a linear, length-wise elastic modulus. The local buckling mode of a flange is controlled by an angle of rotation $\theta$. Initially, the member material is assumed to be linearly elastic with Young's modulus $E$. The critical buckling stress formula for the considered flange types (A, B and C) is 
(a)

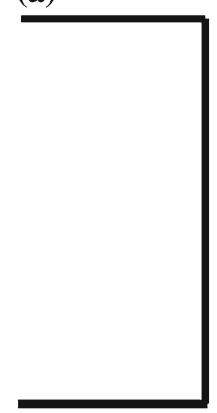

(b)

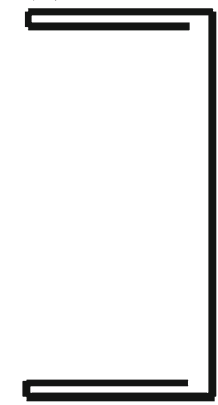

(c)

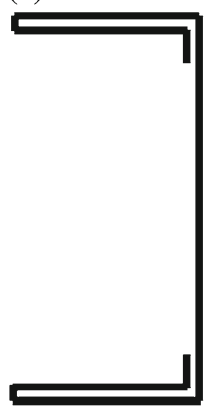

Fig. 1 Types of cross sections under investigation: a type A, $\mathbf{b}$ type B and $\mathbf{c}$ type $\mathrm{C}$

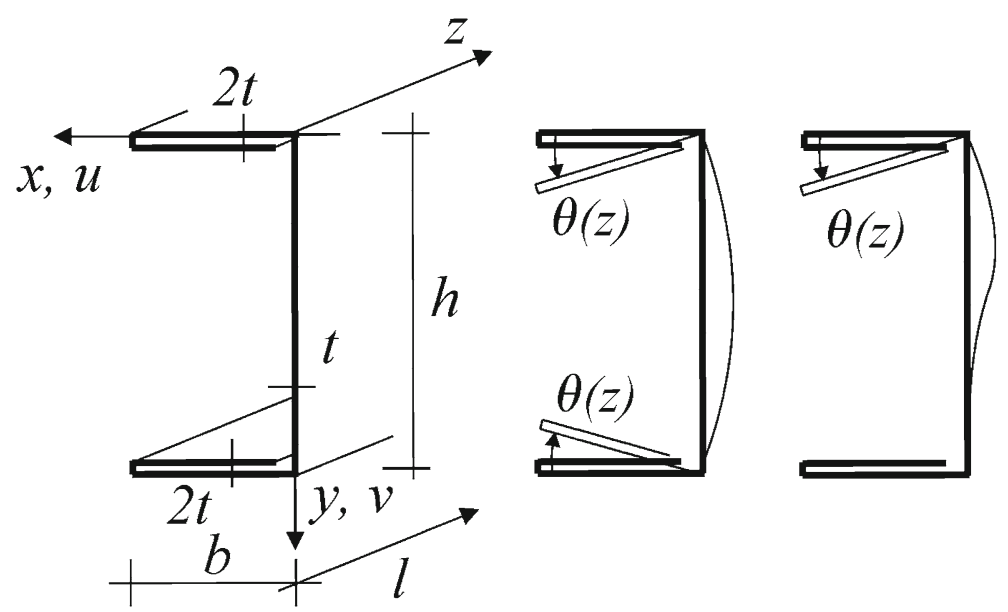

Fig. 2 A Cartesian coordinate system, thin-walled channel, flange displacement

$$
\sigma=E\left(\frac{t}{b}\right)^{2}\left[f_{1} \gamma^{2}\left(\frac{b}{l}\right)^{2}+f_{2} \frac{\chi}{\gamma^{2} b h}+f_{3} \frac{1}{2(1+v)}\right]
$$

where $t$ is the thickness; $b$ is the flange width; $\gamma=n_{\mathrm{W}} \pi / l$, where $n_{\mathrm{W}}$ is the number of half-waves; $h$ is the height of the web; $v$ is Poisson's ratio; and $\chi$ is the coefficient of flange-web cooperation, which is equal to 2 for columns and 4 for beams. The coefficients $f_{1}, f_{2}$ and $f_{3}$ are affected by the cross-sectional dimension of the member, as follows:

- The type A cross sections

$$
f_{1}=1 / 12, \quad f_{2}=1 / 4, \quad f_{3}=1
$$

- The type B cross sections

$$
f_{1}=1 / 2, \quad f_{2}=1 / 8, \quad f_{3}=1
$$

- The type C cross sections

$$
f_{1}=\frac{1+4\left(\frac{a}{b}\right)^{3}}{2\left[1+\frac{3}{2} \frac{a}{b}\left(\frac{t}{b}\right)^{2}\right]}, \quad f_{2}=\frac{1}{8\left[1+\frac{3}{2} \frac{a}{b}\left(\frac{t}{b}\right)^{2}\right]}, \quad f_{3}=\frac{2+\frac{a}{b}}{2\left[1+\frac{3}{2} \frac{a}{b}\left(\frac{t}{b}\right)^{2}\right]}
$$

where $a$ is the crook length.

To find the critical buckling stresses, it is necessary to find the number of half-waves of a buckling mode $n_{\mathrm{w}}$ with the help of Fig. 3.

In Fig. 3, the ratio of the member length to the characteristic length $\eta=l / l_{0}$ is shown, where $l_{0}=$ $\pi b \sqrt[4]{\left(f_{1} h\right) /\left(\chi f_{2} b\right)}$. By dividing the flange length $l$ by the characteristic length $l_{0}$ and incorporating the graph in Fig. 3, it is possible to determine the number of half-waves $n_{\mathrm{w}}$ corresponding to the critical buckling stress. 


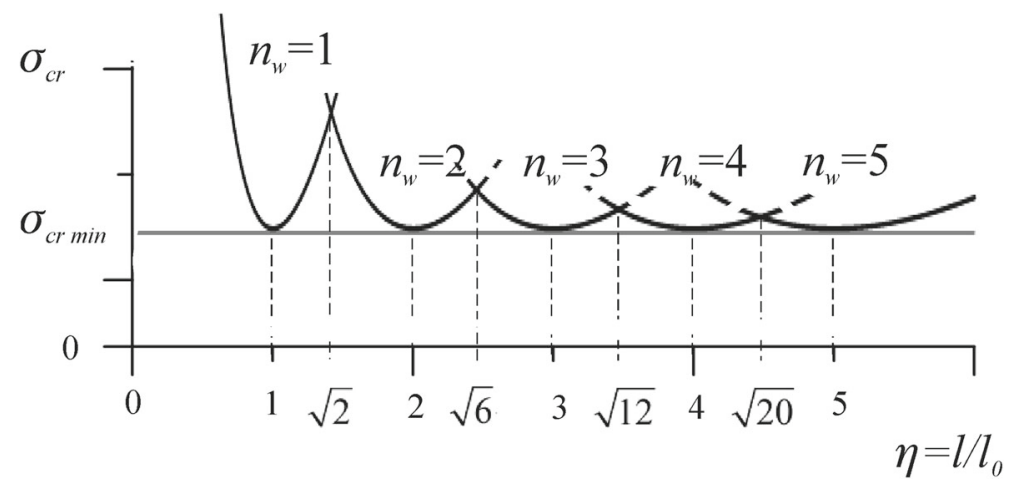

Fig. 3 Critical stress versus ratio of flange length to characteristic one

This information is then inserted into relation (1) to obtain the critical stress $\sigma_{\mathrm{cr}}$ for a linearly elastic material. The details of the analytical solution are presented in my previous research [55].

In this paper, attention is given to the impact of material parameters in the nonlinear range on the buckling stresses. It is assumed that the member material follows the Ramberg-Osgood constitutive law [48]

$$
\varepsilon=\frac{\sigma}{E}+K\left(\frac{\sigma}{\sigma_{0}}\right)^{n-1}
$$

where $\sigma_{0}$ is the yield stress and $K$ and $n$ are material coefficients. To apply the tangent theory to compute the critical stress, the tangent modulus $E_{t}$ is necessary. This modulus is the first stress-strain derivative. Differentiating both sides of relation (5) leads to

$$
E_{t}=\frac{E}{1+\frac{K E(n-1)}{\sigma_{0}}\left(\frac{\sigma}{\sigma_{0}}\right)^{n-2}}
$$

The obtained tangent modulus [10] is inserted into the critical stress formula (1). Next, the relation is derived to transform the linear elastic critical stresses $\sigma_{\mathrm{cr}}$ into the Ramberg-Osgood value, $\sigma_{\mathrm{cr}}^{\mathrm{RO}}$

$$
\sigma_{\mathrm{cr}}^{\mathrm{RO}}+K E(n-1)\left(\frac{\sigma_{\mathrm{cr}}^{\mathrm{RO}}}{\sigma_{0}}\right)^{n-1}=\sigma_{\mathrm{cr}}
$$

More details of the analytical solution for critical stress in the nonlinear range are included in my previous research [56].

Unfortunately, the proposed closed-form analytical solution is a simplified form. The analytical solution is simplified mainly due to the method of modelling the interactions between flange sheets. The analytical solution does not allow for displacements and separation between sheets of flanges.

\section{Numerical approach}

The current problem in this article is extremely complex in both analytical and numerical aspects. In this paper, the numerical model is prepared using ABAQUS software [19]. Structural stability analysis taking the interactions between sheets of flanges into account is a dynamic and nonlinear problem. A nonlinear description is required not only due to the contact phenomenon but also due to a nonlinear material (e.g. aluminium alloy).

The ABAQUS package offers several methods performing dynamic analysis of problems [19]. This analysis distinguishes two procedures: direct-solution dynamic analysis or modal superposition. Direct-solution procedures (such as implicit dynamic analysis, subspace-based explicit dynamic analysis, explicit dynamic analysis, direct-solution steady-state harmonic response analysis) are dedicated to dynamic analysis involving a nonlinear response. Modal superposition procedures (such as mode-based steady-state harmonic response analysis, subspace-based steady-state harmonic response analysis, mode-based transient response analysis, response spectrum analysis, random response analysis, complex eigenvalue extraction) are cost-effective, in the cases of linear or mildly nonlinear dynamic analysis. 
The paper proposes direct-solution dynamic analysis procedures in the meaning of implicit directintegration dynamic analysis. This decision was made because geometrical and material problem nonlinearity is usually assumed to study nonlinear transient dynamic response. Furthermore, general nonlinear dynamic analysis in ABAQUS involves implicit time integration to compute the quasi-static system response, so quasistatic techniques are useful in stability analysis. In the proposed numerical solution using a quasi-static technique, the load is applied smoothly; thus, slow deformation produces a low strain rate. This result implies that infinitely small inertia forces may be neglected. This means that the dynamic effect is small, but the system kinetic energy variation is possible; thus, successive stages of system stability loss happen and the inertia effects are neglected. Theoretical foundations of the indicated numerical techniques are included in $[11,17,19,24,26,27,33,47,49,58,59]$.

The contact phenomenon in stability analysis is a rare issue in research. Attempts to analyse stability incorporating the contact phenomenon were undertaken by K. Magnucki and his group. Due to the complexity of the research problem, they mainly focused on experimental research. The problem of modelling this phenomenon has not yet been thoroughly solved using both analytical and numerical means. In this paper, it is suggested that the interactions between the sheets may be modelled in ABAQUS using surface-to-surface contact discretisation, the finite-sliding tracking approach where the contact pressure is referred to normal behaviour such as a "hard" contact to allow separation after contact and tangential behaviour using the penalty friction formulation $[8,19,60]$. In this type of analysis, when surfaces are in contact, any contact pressure can be transmitted; conversely, when the surfaces are separated, the contact pressure reduces to zero.

Another key element of this paper is the material description. This paper assumes that the material follows a nonlinear pattern. A nonlinear material model can be implemented in ABAQUS by employing deformation plasticity theory based on the Ramberg-Osgood relationship (5) [19,48]. This relationship can successfully be applied in the domain of plastic deformations and to characterise nonlinear elastic materials. The material description in ABAQUS requires the determination of five parameters: $E$-Young's modulus, $v$-Poisson's ratio, $\sigma_{0}$ - the yield stress, $N=n-1$ - the hardening exponent, and $\alpha=K \frac{E}{\sigma_{0}}$ - the "yield" offset, where $K$ and $n$ are the material coefficients.

In this article, a simplified numerical approach is also proposed. This procedure is based on the classical linear stability analysis (LBA). Here, interactions between elements are described in a simplified way. First, a simplified contact model assumes that individual sheets cannot move relative to each other. Separation between sheets is impossible. Next, for material description, an approach is proposed in the analytical solution based on the concept of tangent modulus (6). A similar simplified FEM model was also successfully applied [55]. The limitations and disadvantages of the proposed simplified approach should be kept in mind, and they are briefly summarised in the final discussion.

\section{Examples: analytical and numerical solution}

Let us consider a simply supported channel column and a beam of standard (type A) and nonstandard cross sections (types B and C), as shown in Fig. 4.

The members are composed of two aluminium alloys [50]. The first is a non-heat-treated alloy (Alloy $5056, E=68,670 \mathrm{MPa}, v=0.33, \sigma_{0}=118 \mathrm{MPa}, n=5.62, N=4.62, K=0.002$ and $\left.\alpha=1.1639\right)$, and the second is a heat-treated alloy (Alloy 6081, $E=68,670 \mathrm{MPa}, v=0.33, \sigma_{0}=288 \mathrm{MPa}, n=16.16, N=$ $15.16, K=0.002$ and $\alpha=0.4769$ ). The dry static friction aluminium-on-aluminium friction coefficients range from 1.10 to 1.35 [14]. An average friction coefficient equal to 1.2 is assumed in the studies. Furthermore, it is also assumed in the analysis that the friction coefficient is 0 .

Numerical FEM-based analysis is performed (for types A, B and C cross sections) (ABAQUS [19]), as well as the finite strip method (the case of type A cross section only) and a non-commercial software (CUFSM [30]). To estimate the critical buckling stresses, both simplified linear (LBA) and complex nonlinear (dynamic, implicit, quasi-static) procedures are applied.

During the numerical analysis, the members are modelled using shell elements with a reduced integration type $\mathrm{S} 4 \mathrm{R}$. The main finite element size is $0.002 \times 0.002 \mathrm{~m}^{2}$ (i.e. 160 elements along the type A cross section, 198 elements along the type $\mathrm{B}$ cross section and 210 elements along the type $\mathrm{C}$ cross section). The total number of finite elements in all cases equals 32,000 for type A, 39,600 for type B and 42,000 for type C. Figure 5 presents the numerical models, schematic of the FEM mesh, load and imposed boundary conditions.

In the case of axially compressed columns, it is assumed that the load increases in a single step up to $100 \mathrm{~N}$, and in the case of pure bending, the moment is not greater than $10 \mathrm{Nm}$. 
(a)

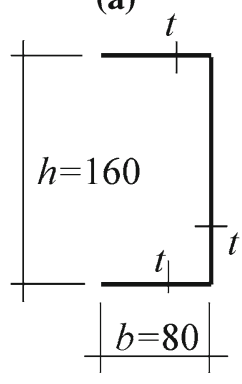

(b)

$2 t$
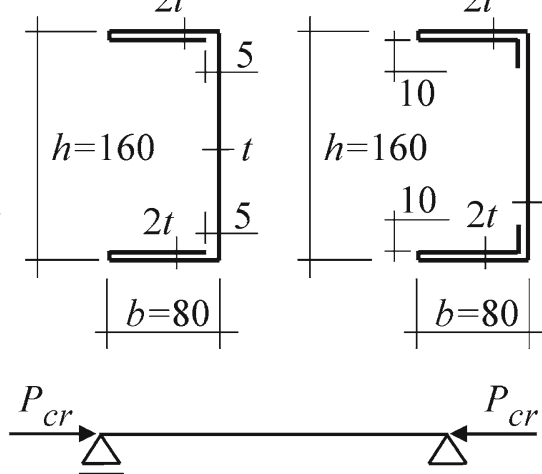

$t=1 ; 2 ; 3 \mathrm{~mm}$

$E=68.67 \mathrm{GPa}$

$\nu=0.33$

[mm]

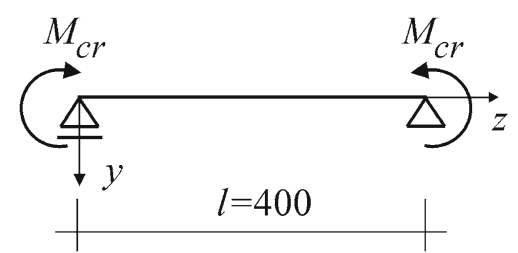

Fig. 4 Examples—data. Thin-walled channel members with different flanges shapes: a type A, b type B and $\mathbf{c}$ type C

(a)

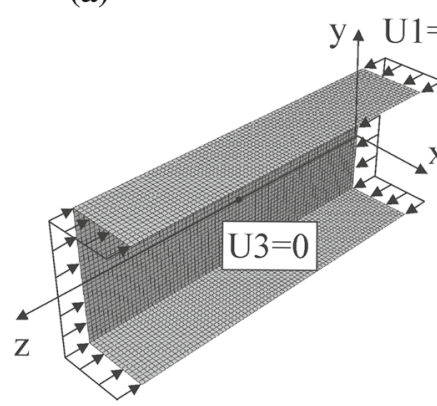

$\mathrm{U} 1=\mathrm{U} 2=0$ (b)
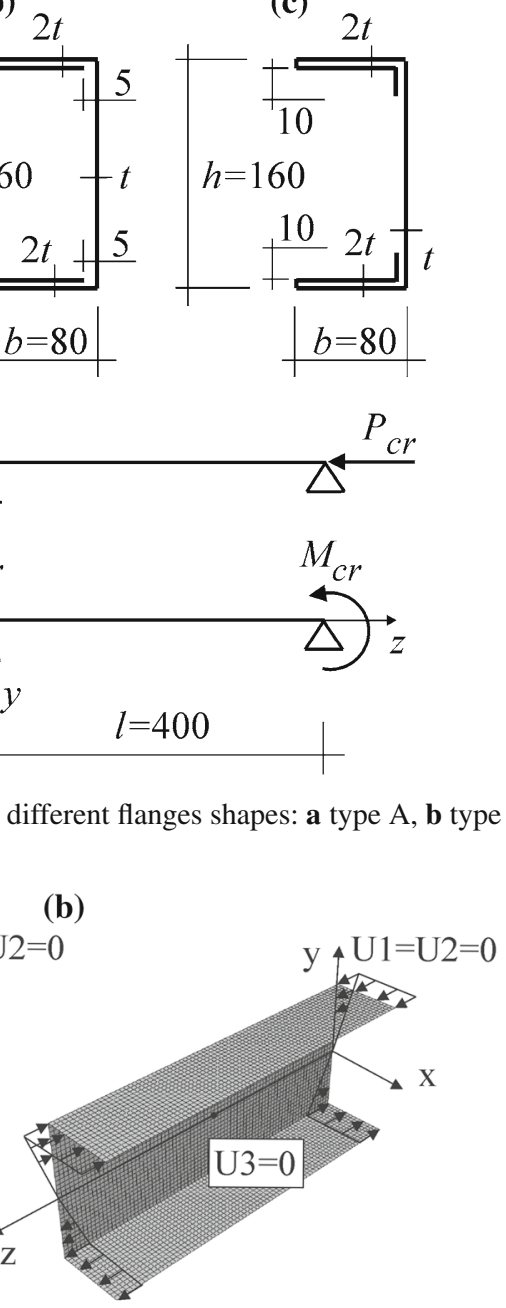

$\mathrm{U} 1=\mathrm{U} 2=0$

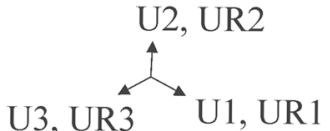

Fig. 5 Three-dimensional FEM models, boundary condition and load diagrams: a axially compressed column and b beam undergoing pure bending

The main analytical and numerical results are presented in Tables 1,2, 3, 4, 5 and 6. Tables 1 and 2 show the results for a standard channel cross section, type A, for axial compression and pure bending, respectively. Similarly, the results for a type B cross section are presented in Tables 3 and 4, and the type C cross-section results are presented in Tables 5 and 6 . Selected solutions from the tables are also presented in figures (see Figs. 6, 7, 8, 9, 10) (limited to wall thickness $t=2 \mathrm{~mm}$ ); they display the relationship between the change in the form of a kinetic energy vs. critical stress. The analytical solutions sufficiently coincide with the numerical ones (FSM, FEM: LBA or quasi-static) both in linear and nonlinear ranges, in the case of A-type cross section (standard channel cross section) because the mean variations do not exceed 5\% (see Tables 1, 2). In other cases, i.e. for B- and C-type cross sections (nonstandard channel cross sections) the variations are larger, about $25 \%$ (see Tables $3,4,5,6$ ). These differences result from the modelling assumptions of connection and interaction between the sheets of flanges. In both analytical approach and FEM (LBA), simplified modelling of interaction/connection is assumed, with neither displacement nor separation between flange sheets. The analytical approach assumes a simplified interaction/connection modelling, excluding displacement or separation between sheets of flanges, unlike the complex approach with normal and tangential interaction, allowing for the post-contact separation. Selected aspects of the obtained results are presented in the next paragraph. 


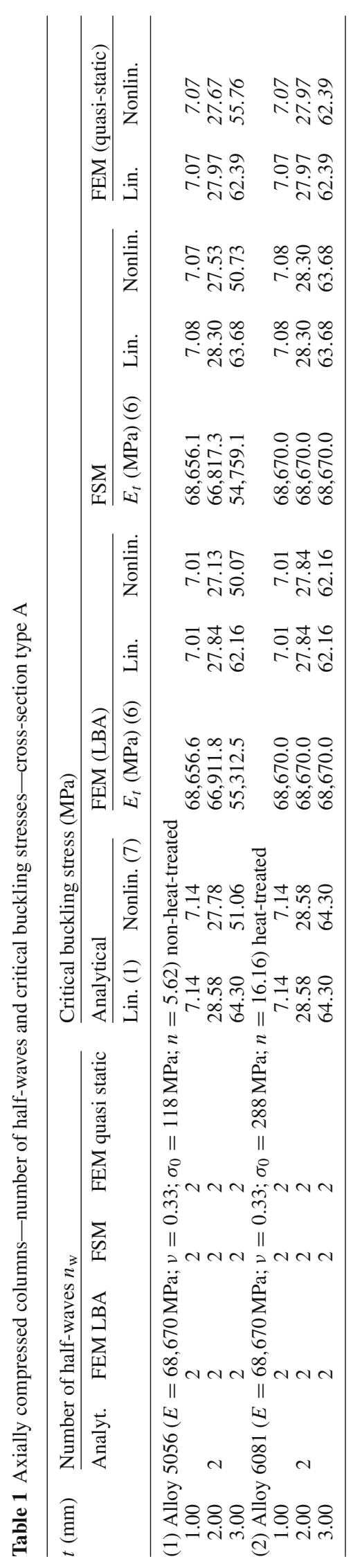




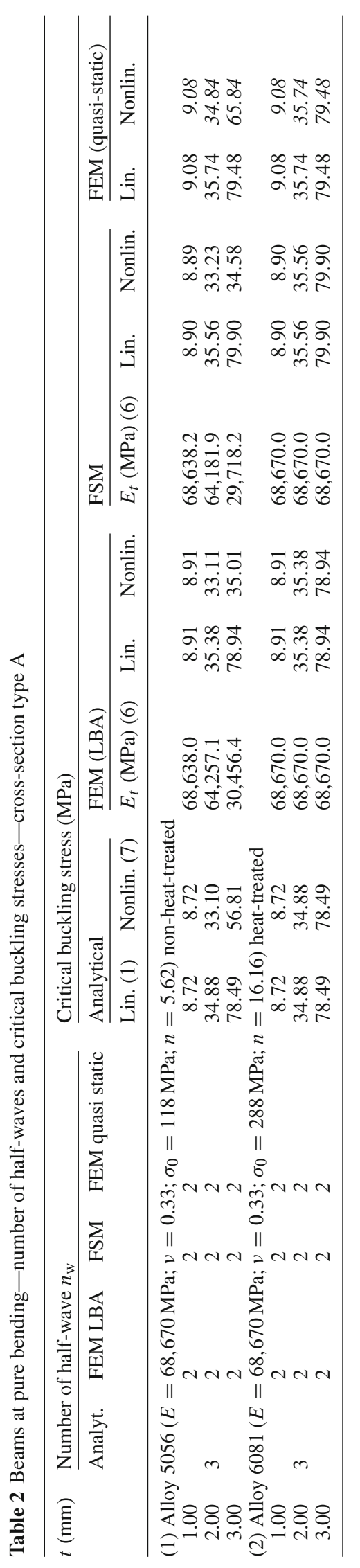




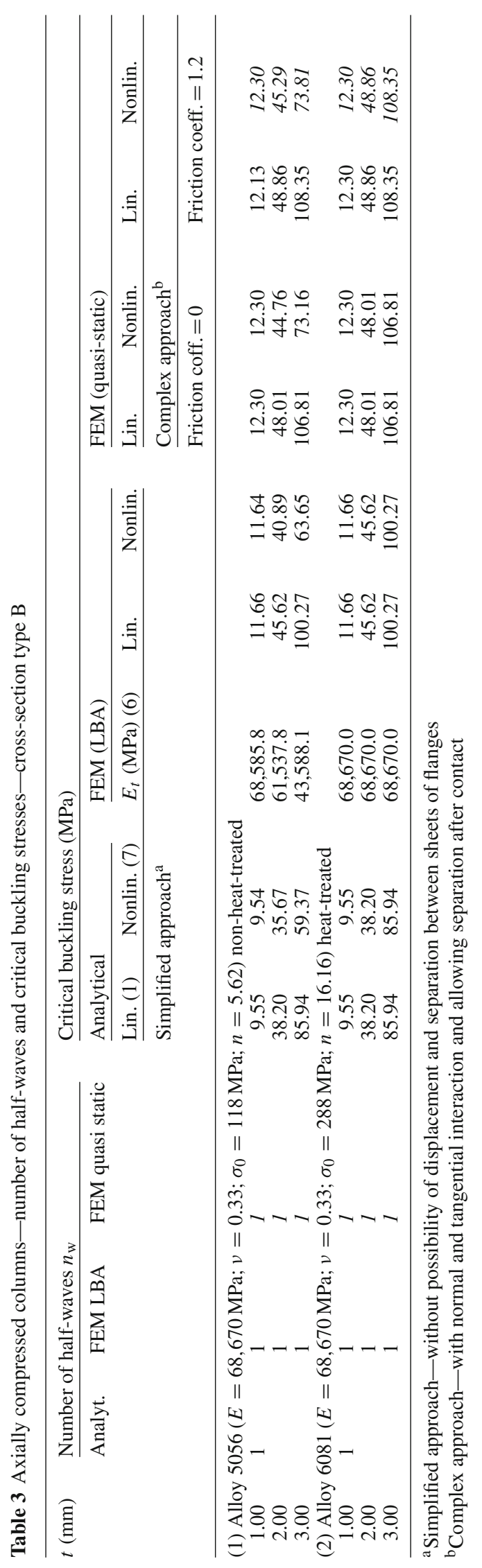




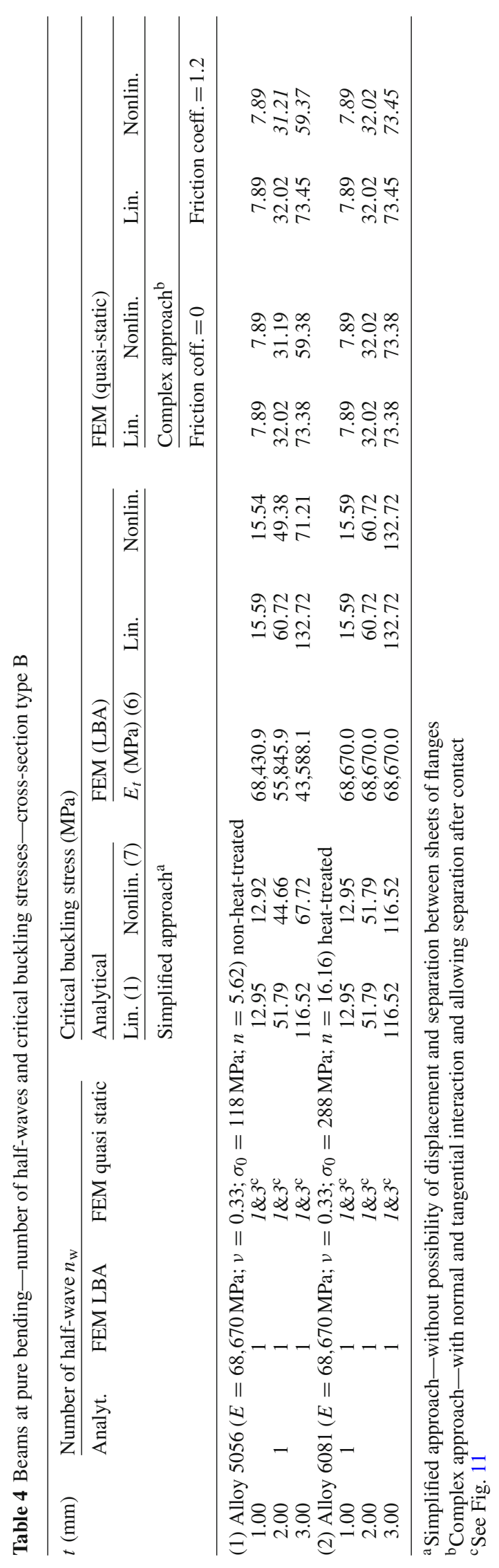




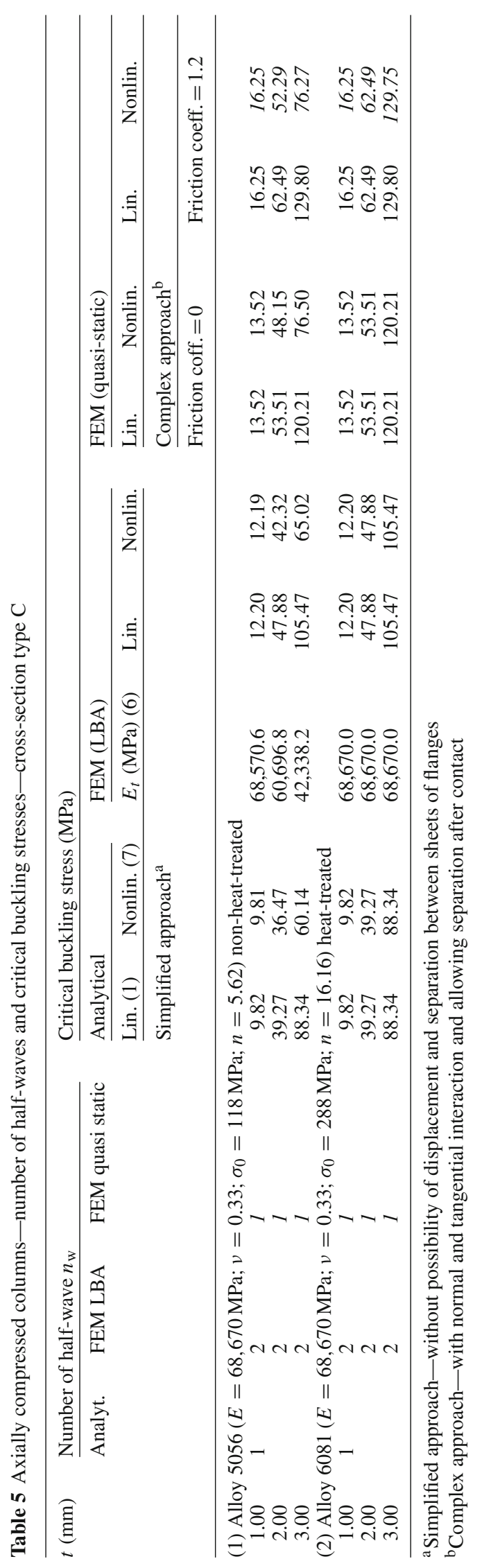




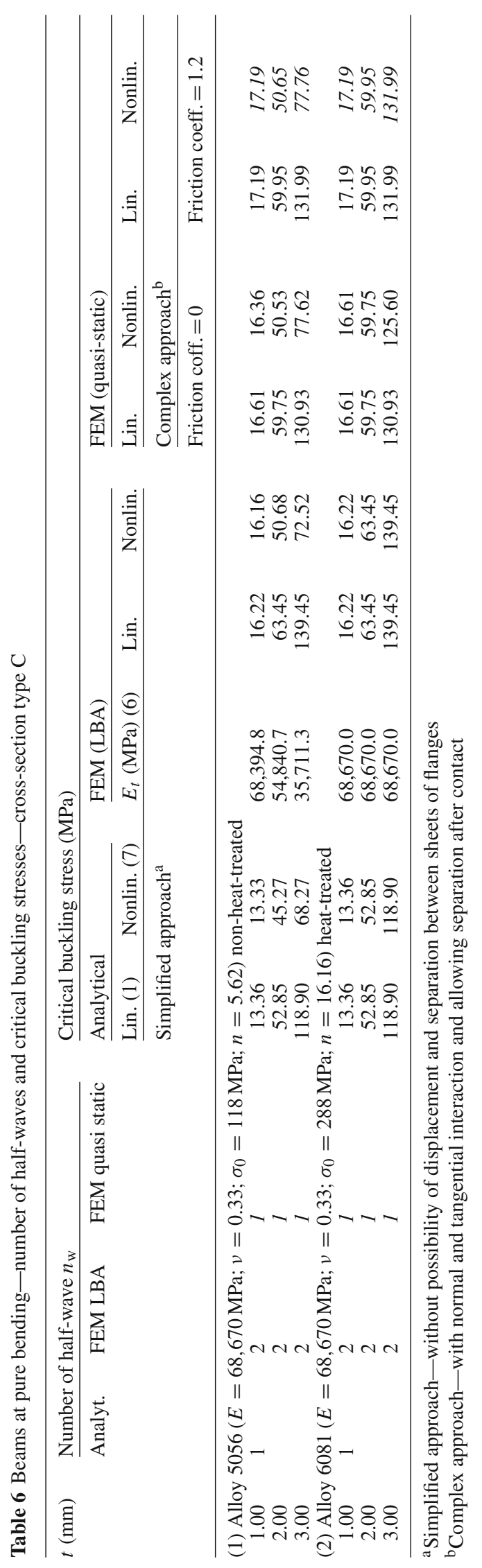


(a)

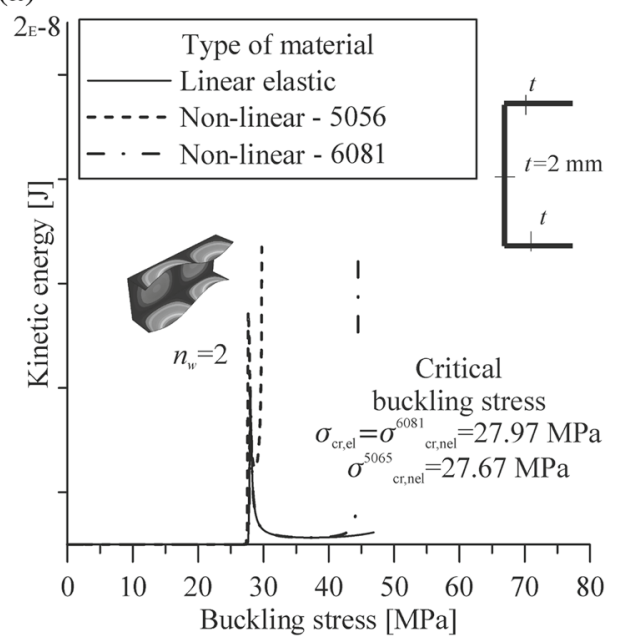

(b)

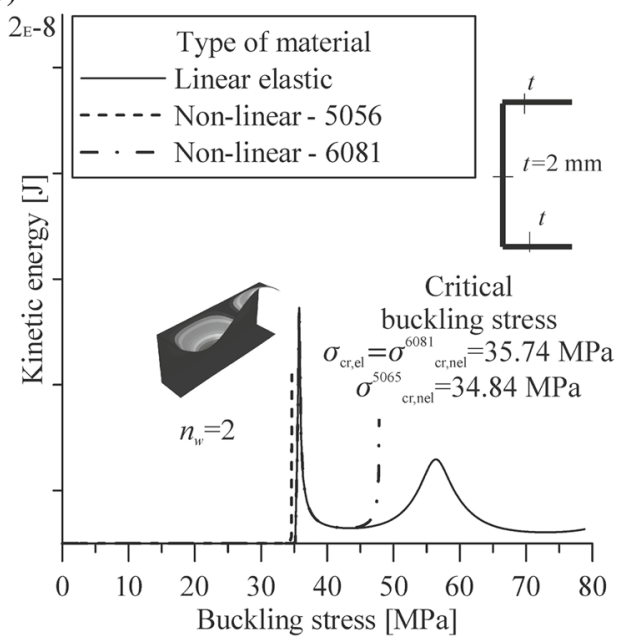

Fig. 6 Kinetic energy versus critical buckling stress at linear and nonlinear elastic material—aluminium alloys 5056 and $6081-\mathbf{a}$ axially compressed column, b beams at pure bending

(a)

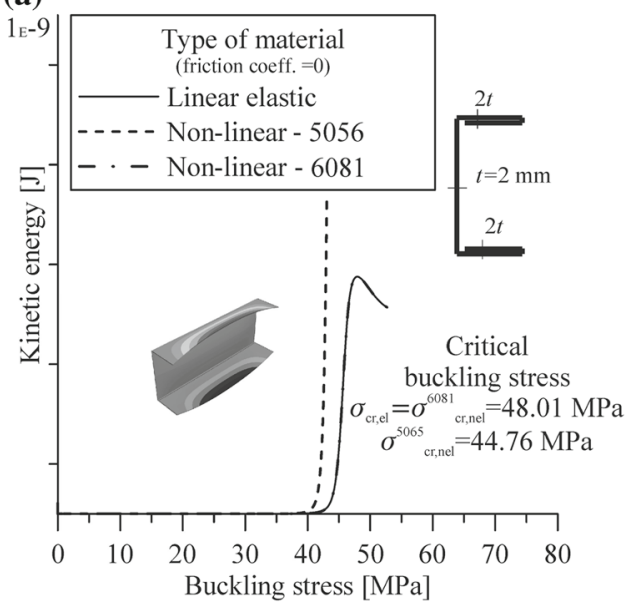

(b)

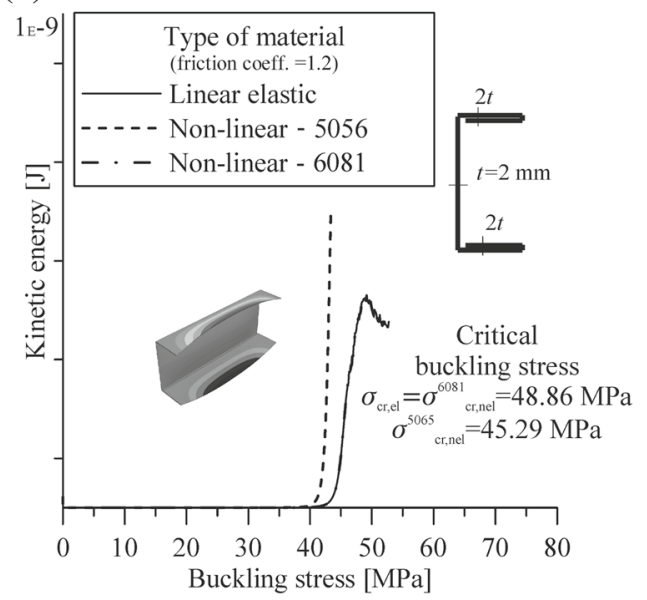

Fig. 7 Kinetic energy versus critical buckling stress at linear and nonlinear elastic material—aluminium alloys 5056 and 6081 axially compressed column, a friction coefficient $=0, \mathbf{b} 1.2$

\section{Discussion and conclusions}

This paper presents numerical and analytical solutions for a local buckling problem of compressed columns and beams. Numerical quasi-static FEM-based techniques (ABAQUS) are proposed to estimate the critical stresses for standard and primarily nonstandard cross sections. Furthermore, simplified analytical solutions (closedform formulae) and numerical procedures are also introduced. The impact of material nonlinearity on structural stability analysis is also emphasised in this paper. Moreover, the difference between the proposed numerical and analytical approaches is presented. Due to versatility and generality, in the domain of all available stability analysis techniques [19], attention is paid to the proposed nonlinear implicit dynamic analysis involving a quasi-static response of systems. Due to the applied approach, unlike, for example, Riks method, a possibility exists to follow the changes in kinetic energy, what especially important in buckling analysis, because stability loss is an inherently dynamic phenomenon. Additionally, it should be noted that the basic algorithm of the Riks method converges with the Newton method. Hence, in numerous material and loading cases, a path-dependent response is about to come. Thus, the solutions may be affected by an increment size. In contrast to the Riks method, the energetic approach uniquely determines the value of critical stress and the corresponding mode of stability loss. Furthermore, equilibrium path can be determined very precisely on the basis of kinetic energy 
(a)

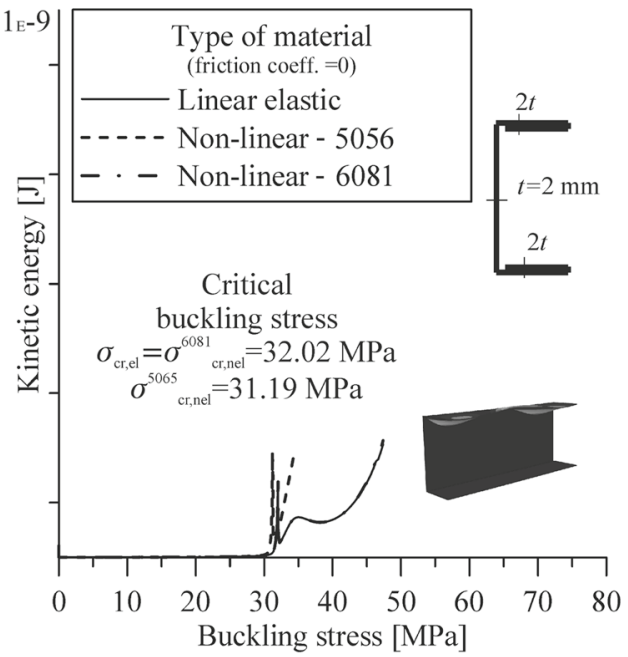

(b)

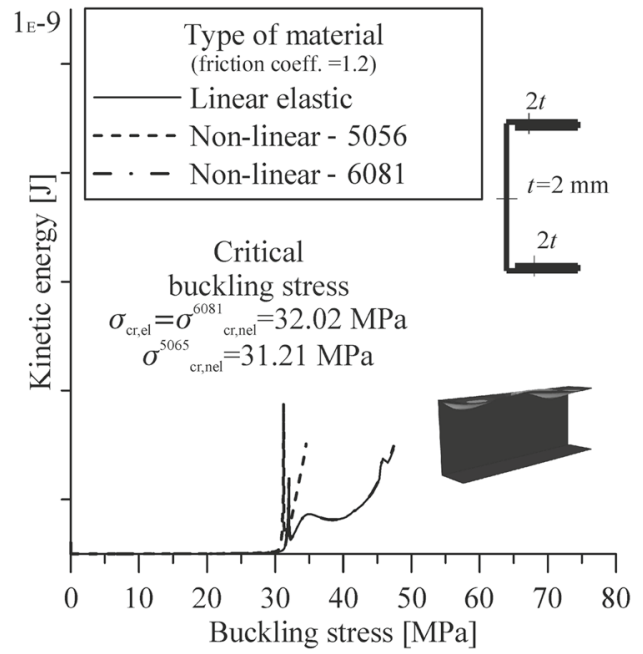

Fig. 8 Kinetic energy versus critical buckling stress at linear and nonlinear elastic material—aluminium alloys 5056 and 6081 beams at pure bending, a friction coefficient $=0, \mathbf{b} 1.2$

(a)

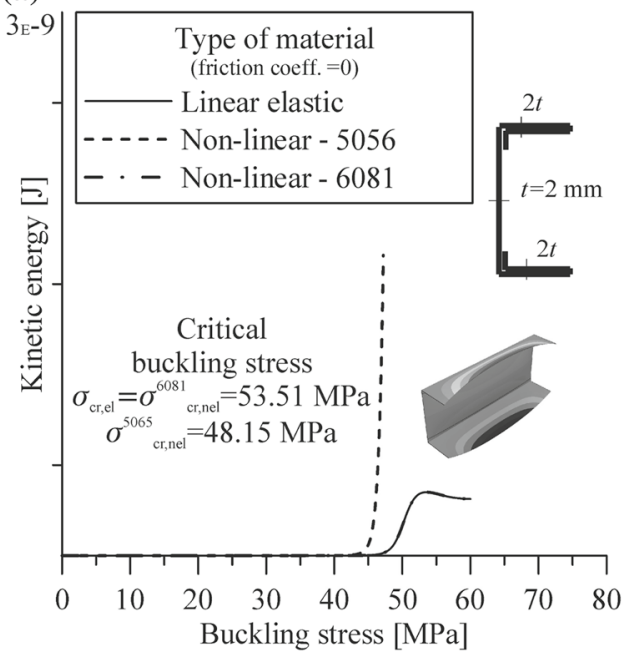

(b)

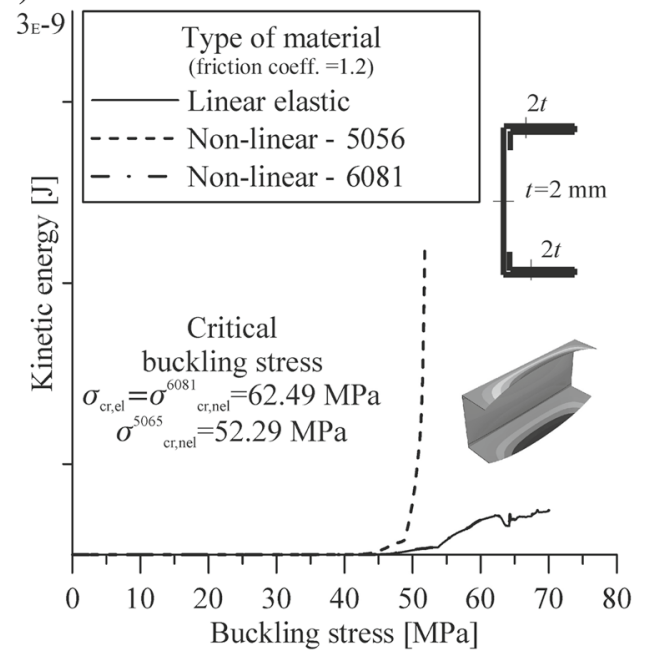

Fig. 9 Kinetic energy versus critical buckling stress at linear and nonlinear elastic material—aluminium alloys 5056 and 6081 axially compressed column, a friction coefficient $=0, \mathbf{b} 1.2$

variation. The recommended dynamic solution technique is undoubtedly useful, relevant in stability analysis of any linear or nonlinear systems. It seems to be currently the only available accurate method to analyse such complex phenomena.

To fully confirm the proposed solutions, experimental studies are highly anticipated. Notwithstanding, the proposed numerical technique is demanding due to computational time. For this reason, some simplified solutions have been proposed. The proposed closed-form solutions satisfactorily correspond to the numerical results (in the tables, the comparative solutions are highlighted in italics). The analytical critical stress values are generally less than the numerical ones, but not always. The differences between solutions are not larger than $0-40 \%$ (please see solutions in Tables 1, 2, 3, 4, 5, 6 for details). The greatest differences appear when the numerical flange displacements (see Fig. 11) significantly differ from the theoretical assumptions (see Fig. 12). However, if the cross section is standard or there are no significant displacements between flange sheets, then the solutions are equal, even in the case of nonstandard cross sections. Note that the analytical solution variant significantly reduces the working time, which is important from the design perspective. 
(a)

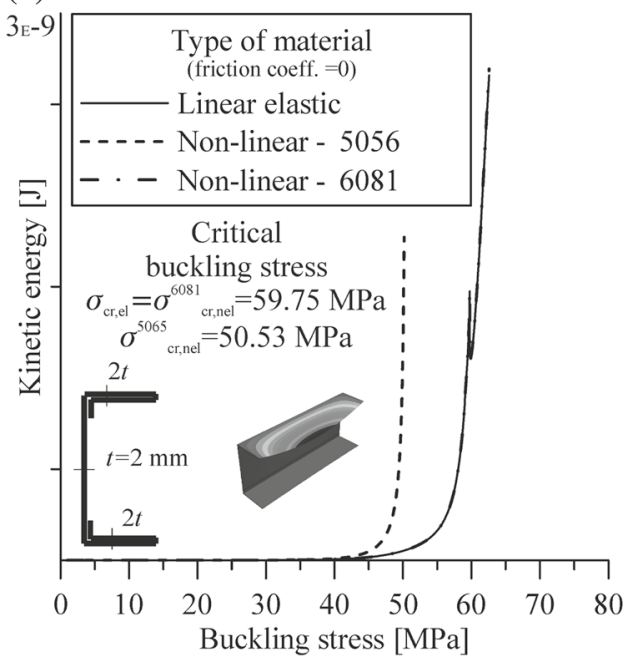

(b)

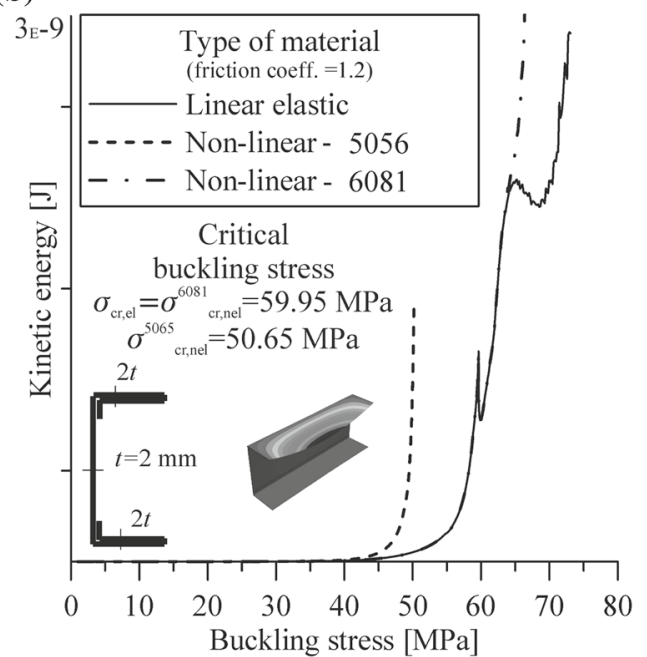

Fig. 10 Kinetic energy versus critical buckling stress at linear and nonlinear elastic material—aluminium alloys 5056 and 6081 beams at pure bending, $\mathbf{a}$ friction coefficient $=0, \mathbf{b} 1.2$

(a)

\section{Cross-section type B}

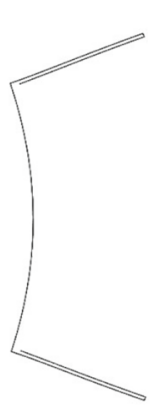

(b)

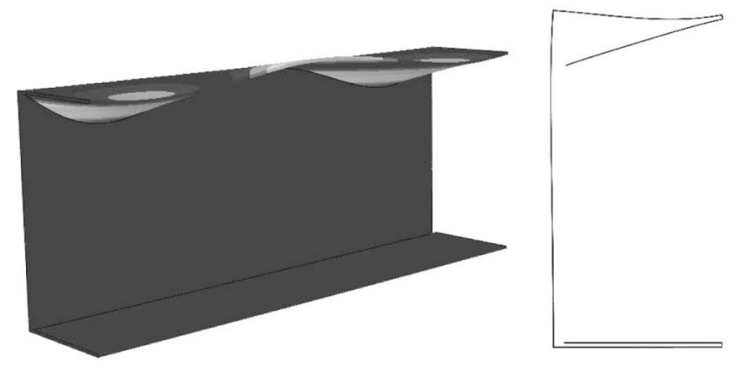

\section{Cross-section type C}
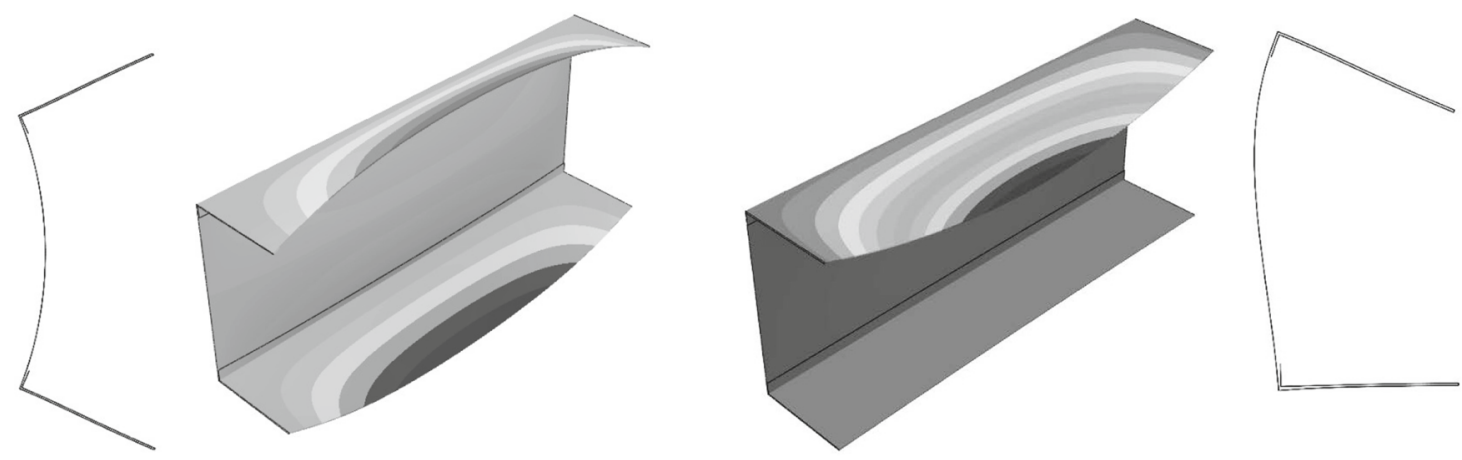

Fig. 11 FEM complex approach solutions (with normal and tangential interaction and allowing separation after contact)—buckling modes in the case of type $\mathrm{B}$ and $\mathrm{C}$ cross sections: $\mathbf{a}$ axially compressed columns and $\mathbf{b}$ beams undergoing pure bending

The proposed simplified method of numerical analysis (LBA) incorporating the concept of tangent modulus $E_{t}(6)$ is correct only in the cases where the critical buckling stress is significantly less than the yield stress. Furthermore, the pattern of cross-sectional deformation highly affects the solution. In the simplified numerical solution, similar to the analytical solution, it is assumed that the flange sheets do not move relative to each 
(a)

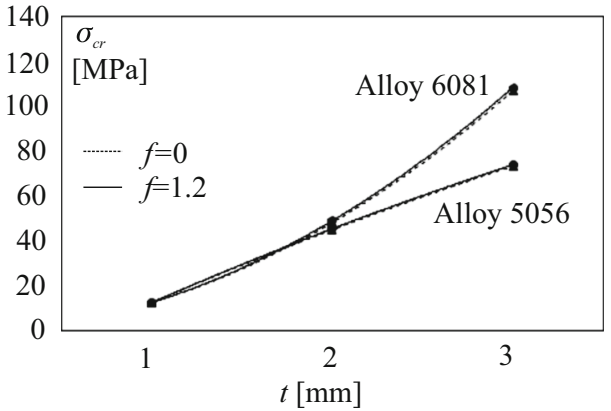

(b)

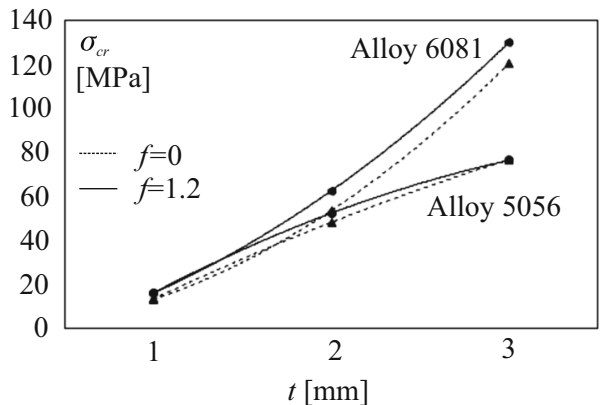

Fig. 12 Influence of friction coefficient on critical stress expressed by dependence of trend line of critical buckling stress versus wall thickness in the case of type $\mathbf{a} \mathrm{B}$ and $\mathbf{b} \mathrm{C}$ cross sections for axially compressed columns made of nonlinear material at complex approach of contact

(a)

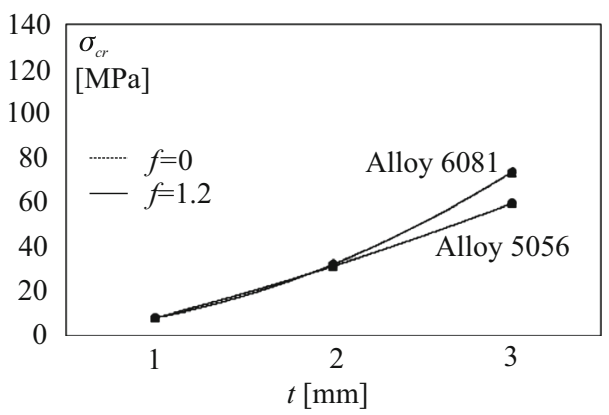

(b)

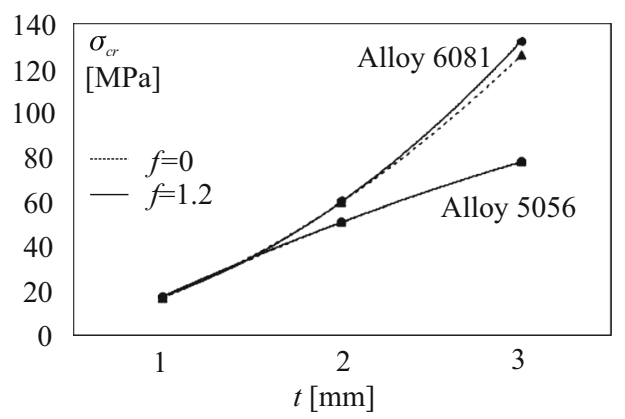

Fig. 13 Influence of friction coefficient on critical stress expressed by dependence of trend line of critical buckling stress versus wall thickness in the case of type $\mathbf{a} \mathrm{B}$ and $\mathbf{b} \mathrm{C}$ cross sections for beams undergoing pure bending made of nonlinear material at complex approach of contact

other. Deviations from these assumptions lead to computational errors. This analytical method of analysis is not demanding due to computational time.

The tested cold-formed thin-walled members are composed of two aluminium alloys. One of the tested alloys is heat-treated (6081 alloy), whereas the other is not heat-treated (5056 alloy). The stability analysis of aluminium members is highly sensitive to material nonlinearity in the case of non-heat-treated alloys. The buckling stresses in the case of non-heat-treated alloys may be significantly lower (in the analysed examples, the difference did not exceed $42.1 \%$ ) than in the case not involving nonlinearity of the material (see the results in Tables 1, 2, 3, 4, 5, 6). From an engineering perspective, neglecting the influence of material nonlinearity can lead to significant analytical errors.

In the case of nonstandard type $\mathrm{B}$ cross section at pure bending, a greater cross-sectional area compared to the type A channel did not cause the response to improve, which means that the critical stress value was not higher. This type B cross section led to instability faster than a simple, classic channel cross section (type A). Note that in the case of cold-formed thin-walled structures, whose prime design direction is the stability loss, increasing the cross-sectional area is not always safe.

Including the real friction between sheets of flange in the buckling analysis does not have a big impact on the values of critical buckling stresses. The difference did not exceed 10\% (see Figs. 12, 13).

It is unacceptable, however, in the stability analysis to completely disregard the influence of interaction between the sheets of flange. In the buckling analysis, this impact must be taken into account; otherwise allowing the penetration of the sheets of flanges, we will make a major error (even 100\% [55]) in the assessment of the value of buckling stress and of course in the buckling mode.

Furthermore, numerical studies have shown that initial geometric imperfections may significantly impact stability loss and the critical stress values. Stability analyses of cold-formed thin-walled structures should take initial geometric imperfections into account. As stated, during numerical research even small initial imperfections may cause major variations in structural performance. Nevertheless, this issue was deliberately 
omitted at article due to its complexity of problem and volume of the paper. The author, however, feels obliged to signal the problem at least in the commentary.

Finally, note that the proposed energy method, despite its disadvantages, allows the critical buckling stresses to be precisely determined. This method allows precisely following the entire structural performance under an active load in linear and nonlinear elastic and inelastic ranges.

Acknowledgements The calculations presented in this paper were carried out at the TASK Academic Computer Centre in Gdańsk, Poland.

Open Access This article is distributed under the terms of the Creative Commons Attribution 4.0 International License (http:// creativecommons.org/licenses/by/4.0/), which permits unrestricted use, distribution, and reproduction in any medium, provided you give appropriate credit to the original author(s) and the source, provide a link to the Creative Commons license, and indicate if changes were made.

\section{Compliance with ethical standards}

Conflict of interest The author declares that he has no conflict of interest.

\section{References}

1. GBTUL 2.0 buckling and vibration analysis of thin-walled members (2013). www.civil.ist.utl.pt/gbt

2. Ádány, S.: Constrained shell finite element method for thin-walled members, part 1: constraints for a single band of finite elements. Thin Walled Struct. (2017). https://doi.org/10.1016/j.tws.2017.01.015

3. Ádány, S., Schafer, B.: Generalized constrained finite strip method for thin-walled members with arbitrary cross-section: Primary modes. Thin Walled Struct. 84, 150-169 (2014)

4. Ádány, S., Schafer, B.: Generalized constrained finite strip method for thin-walled members with arbitrary cross-section: secondary modes, orthogonality, examples. Thin Walled Struct. 84, 123-133 (2014)

5. Ádány, S., Visy, D., Nagy, R.: Constrained shell finite element method, part 2: application to linear buckling analysis of thin-walled members. Thin Walled Struct. (2017). https://doi.org/10.1016/j.tws.2017.01.022

6. Altenbach, H., Eremeyev, V.: Thin-walled structures made of foams. In: Altenbach, H., Oechsner, A. (eds.) Cellular and Porous Materials in Structures and Processes, pp. 167-242. Springer, Vienna (2010)

7. Anbarasu, M.: Local-distortional buckling interaction on cold-formed steel lipped channel beams. Thin Walled Struct. 98, 351-359 (2016)

8. Barber, J., Ciaverella, M.: Contact mechanics. Int. J. Solid Struct. 37, 29-43 (2000)

9. Basaglia, C., Comotim, D., Goncalves, R., Biscaya, A.: GTB-based assessment of the buckling behavior of cold-formed steel purlins restrained by sheeting. Thin Walled Struct. 72, 217-229 (2013)

10. Basquin, O.: Tangent modulus and the strength of steel columns in test. Technical report, Department of Commerce, Bureau of Standards, USA (1924)

11. Brush, D., Almroth, B.: Buckling of Bars, Plates and Shells. McGraw-Hill, New York (1975)

12. Davies, J.: Recent research advances in cold-formed steel structures. J. Constr. Steel Res. 55, 267-288 (2000)

13. Davies, J., Dubina, D., Laboube, R., Rasmussen, K., Rondal, J.: Light Gauge Metal Structures Recent Advances. CISM Courses and Lectures No. 455. Springer, Berlin (2003)

14. Davis, J. (ed.): Concise Metals Engineering Data Book. ASM International, Materials Park (2010)

15. Eremeyev, V., Pietraszkiewicz, W.: Refined theories of plates and shells. J. Appl. Math. Mech. 94(1-2), 5-6 (2014)

16. Gabriele, S., Rizzi, N., Varano, V.: A 1D higher gradient model derived from Koiter's shell theory. Math. Mech. Solids 21(6), 737-746 (2014)

17. Gajewski, A., Zyczkowski, M.: Optimal Structural Design Under Stability Constraints. Kluwer Academic Publishers, Dordrecht (1988)

18. Giorgio, I., Corte, A.D., dell'Isola, F., Steigmann, D.: Buckling modes in pantographic lattices. C. R. Méc. 344, 487-501 (2016)

19. Habbit, D., Karlsson, B., Sorensen, P.: ABAQUS Theory Manual. Hibbit, Karlsson, Sorensen Inc, Providence

20. Hancock, G.: Cold-formed steel structures. J. Constr. Steel Res. 59, 473-487 (2003)

21. Hancock, G.: Cold-formed steel structures: research review 2013-2014. Adv. Struct. Eng. 19(3), 393-408 (2016)

22. Hancock, G., Pham, C.: Buckling analysis of thin-walled sections under localised loading using the semi-analytical finite strip method. Thin Walled Struct. 86, 35-46 (2015)

23. Kissell, J., Ferry, R.: Aluminum Structures, A Guide to Their Specifications and Design. Wiley, New York (2002)

24. Koiter, W.: W.T. Koiter's Elastic Stability of Solids and Structures. Cambridge University Press, Cambridge (2009)

25. Kumar, J., Jayachandran, S.: Experimental investigation and evaluation of direct strength method on beam-column behavior of uprights. Thin Walled Struct. 102, 165-179 (2016)

26. LaSalle, J.: The stability of dynamical systems. Hamilton Press (1976)

27. LaSalle, J.: The Stability and Control of Discrete Processes. Springer, Berlin (1986)

28. Leng, J., Li, Z., Guest, J., Schafer, B.: Shape optimization of cold-formed steel columns with fabrication and geometric end-use constraints. Thin Walled Struct. 85, 271-290 (2014) 
29. Li, Z., Abreu, J., Leng, J., Schafer, B.: Review: constrained finite strip method developments and applications in cold-formed steel design. Thin Walled Struct. 81, 2-18 (2014)

30. Li, Z., Schafer, B.: CUFSM elastic buckling analysis of thin-walled members with general end boundary conditions. http:// www.ce.jhu.edu/bschafer/cufsm/

31. Luongo, A., D'Annibale, F.: Nonlinear hysteretic damping effects on the post-critical behaviour of the visco-elastic Beck's beam. Math. Mech. Solids 22(6), 1347-1365 (2016)

32. Luongo, A., Ferretti, M., Seyranian, A.: Effects of damping on the stability of the compressed Nicolai beam. Math. Mech. Complex Syst. 3(1), 1-26 (2015)

33. Lyapunov, A.: The General Problem of the Stability of Motion. Taylor \& Francis, London (1992)

34. Magnucka-Blandzi, E., Magnucki, K.: Buckling and optimal design of cold-formed thin-walled beams: review of seleted problems. Thin Walled Struct. 49, 554-561 (2011)

35. Magnucki, K., Paczos, P., Kasprzak, J.: Elastic buckling of cold-formed thin-walled channel beams with drop flanges. J. Struct. Eng. 136(7), 886-896 (2010)

36. Magnucki, K., Szyc, W., Stasiewicz, P.: Stress state and elastic buckling of a thin-walled beam with monosymmetrical open cross-section. Thin Walled Struct. 42, 25-38 (2004)

37. Martins, A., Camotim, D., Dinis, P.: Local-distortional interaction in cold-formed steel beams: behaviour, strength and DSM design. Thin Walled Struct. 119, 879-901 (2017)

38. Martins, A., Landesmann, A., Camotim, D., Dinis, P.: Distortional failure of cold-formed steel beams under uniform bemding: behaviour, strength and DSM design. Thin Walled Struct. 118, 196-213 (2017)

39. Mazzolani, F.: Aluminum Alloy Structures. E\&FN Spon, New York (1995)

40. Mazzolani, F.: Aluminum Structural Design, vol. 442. Springer, Wien (2003)

41. Nguyen, V., Pham, C., Cartwright, B., English, M.: Design of new cold rolled purlins by experimental testing and direct strength method. Thin Walled Struct. 118, 105-112 (2017)

42. Paczos, P.: Experimental and numerical (FSM) investigations of thin-walled beams with double-box flanges. J. Theor. Appl. Mech. 51(2), 497-504 (2013)

43. Paczos, P.: Exprimental investigation of C-beams with non-standard flanges. J. Constr. Steel Res. 93, $77-87$ (2014)

44. Paczos, P., Wasilewicz, P.: Experimental investigation of buckling of lipped, cold-formed thin-walled beams with I-section. Thin Walled Struct. 47, 1354-1362 (2009)

45. Pham, C., Hancock, G.: Experimental investigation and direct strength design of high-strength, complex C-sections in pure bending. J. Struct. Eng. 139(11), 1842-1852 (2013)

46. Piccardo, G., Ferrarotti, A., Luongo, A.: Nonlinear generalized beam theory for open thin-walled members. Math. Mech. Solids 22(10), 1907-1921 (2016)

47. Pignataro, M., Rizzi, N., Luongo, A.: Stability, Bifurcation and Postcritical Behaviour of Elastic Structures. Elsevier, Amsterdam (1991)

48. Ramberg, W., Osgood, W.: Description of stress-strain curves by tree parameters. Technical report, National Advisory Committee for Aeronautics (1943)

49. Ramm, E.: Nonlinear Finite Element Analysis in Structural Mechanics. Springer, Berlin (1981)

50. Rasmussen, K., Ronald, J.: Strength curves for aluminium alloy columns. Eng. Struct. 23, 1505-1517 (2000)

51. Rendall, M., Hancock, G., Rasmussen, K.J.R.: The generalised constrained finite strip method for thin-walled members in shear. Thin Walled Struct. 117, 294-302 (2017)

52. Rizzi, N., Varano, V.: The effects of warping on the postbuckling behaviour of thin-walled structures. Thin Walled Struct. 49(9), 1091-1097 (2011)

53. Sarawit, A.: CUTWP global buckling analysis of thin-walled members. http://www.ce.jhu.edu/bschafer/cutwp/

54. Scerrato, D., Giorgio, I., Rizzi, N.: Three-dimensional instabilities of pantographic sheets with parabolic lattices: numerical investigations. ZAMP - Zeitschrift für angewandte Mathematik und Physik 67(53), 1-19 (2016)

55. Szymczak, C., Kujawa, M.: On local buckling of cold-formed channel members. Thin Walled Struct. 106, 93-101 (2016)

56. Szymczak, C., Kujawa, M.: Local buckling of thin-walled channel member flange made of aluminum alloy. In: AIP Conference Proceedings, vol. 1822, no. 1, pp. 020014-1-8 (2017)

57. Taig, G., Ranzi, G., D’Annibale, F.: An unconstrained dynamic approach for the generalised beam theory. Contin. Mech. Thermodyn. 27(4-5), 879-904 (2015)

58. Timoshenko, S., Gere, J.: Theory of Elastic Stability. McGraw-Hill, New York (1961)

59. Waszczyszyn, Z., Cichoń, C., Radwańska, M.: Stability of Structures by Finite Element Methods. Studies in Applied Mechanics, vol. 40. Elsevier, Amsterdam (1994)

60. Wriggers, P.: Computational Contact Mechanics. Springer, Berlin (2006)

61. Ye, J., Hajirasouliha, I., Becque, J., Pilakoutas, K.: Development of more efficent cold-formed steel channel sections in bending. Thin Walled Struct. 101, 1-13 (2016)

62. Yu, C., Schafer, B.: Simulation of cold-formed steel beams in local and distortional buckling with applications to the direct strength method. J. Constr. Steel Res. 63, 581-590 (2007)

Publisher's Note Springer Nature remains neutral with regard to jurisdictional claims in published maps and institutional affiliations. 